$\xi=-1$

\title{
Leg Length Discrepancy Effects on Range of Motion in Lower Limb During Walking
}

\author{
N. A. Azizan ${ }^{1 *}$, D. A. Salhani ${ }^{1}$, K. S. Basaruddin' ${ }^{1}$ A. F. Salleh ${ }^{1}$, W. M. R. Rusli ${ }^{1}$, A. R. Sulaiman ${ }^{2}$ \\ ${ }^{1}$ School of Mechatronic Engineering, Universiti Malaysia Perlis, 02600 Pauh Putra, Perlis, Malaysia. \\ ${ }^{2}$ Department of Orthopaedics, School of Medical Science, Universiti Sains Malaysia, 16150 Kubang Kerian, Kelantan, Malaysia \\ * Corresponding author E-mail: nurul.azira91@yahoo.com
}

\begin{abstract}
Leg length discrepancy (LLD) refers to the medical condition where both legs are noticeable unequal length that could affect the gait and posture, thus may lead to various orthopedic disorders that can have serious repercussions on the individual. In order to ameliorate the rehabilitation of individuals with LLD, it is important to understand the biomechanics of LLD in these individuals. This paper presents a study to investigate on the effect of LLD on the hip and knee joint range of motion. Sandal with insoles was used to simulate the artificial LLD. The sandal's thickness was increased starting from $0.5 \mathrm{~cm}$ up to $4.0 \mathrm{~cm}$ with $0.5 \mathrm{~cm}$ increment. Eighteen healthy subject need to walk over two force plates. Visual 3D and Qualisys Track Manager (QTM) system were employed for data processing. ROM was compared using the one-way blocked analysis of variance and paired t-test. The results showed that a statistically significance difference in hip and knee ROM for long leg in frontal and sagittal direction, respectively. The ROM for hip was found significance at the minimum LLD level of $2.5 \mathrm{~cm}$ while for knee at $1.0 \mathrm{~cm}$. No significance difference found in hip and knee ROM for short leg.
\end{abstract}

Keywords: Discrepancy; Hip Joint; Knee Joint; Range of Motion.

\section{Introduction}

Leg length discrepancy (LLD) is a prevalent condition and it occur in up to $70 \%$ of the population with a mean discrepancy of $0.5 \mathrm{~cm}$ [1], [2]. LLD also known as leg length inequality (LLI) or short leg syndrome, which means either one of the legs is longer or shorter. It is also known as leg length insufficiency or anisomelia [3]. LLD classified into three types according to the way that LLD can occurs. They are anatomical (also known structural), functional (also called apparent) or environmental LLD and this type of LLD is a combinational of anatomical and functional LLD [4]-[6]. Anatomical or structural LLD is a caused due to actual bony asymmetry existing between the level of the femur head and the calcaneus. Functional or apparent LLD is due to muscular weakness or inflexibility at the pelvis or foot and ankle complex. For instance, unilateral pronation may cause an apparent shortening of the leg [7], [8]. A third type is common in people who run or walk on a sloping surface in one direction and for long periods of time. Anatomical type can be classified into three classes. It can be congenital that occur from the birth, developmental from a childhood disease or injury that slows or damages the growth plates, or posttraumatic that results from surgical treatment of fractures that prompts shortening the end of the bone [9].

Our study is focusing on males only, while Resende et al., [10] studied female only. They found that both legs were significance difference by LLD as there was smaller knee and hip flexion angles on the short leg and greater knee and hip flexion angles on the long leg. Moreover, Resende et al. [11] was included both male and female. The result shows that different genders have different kinematics affect caused by LLD [12]. In the case of males, the short leg reduced the range of motion and increased in the long leg [13]. While females showed opposite results [14]. Furthermore,
Khamis et al., [15] reported the study on the effect of LLD on biomechanics during gait and they found that both legs have a significance difference. Contradict to Azira et al., [11] who found that short limb was initially shows significance at the minimum LLD level of $2.0 \mathrm{~cm}$. The short limb presented increase of flexion during midstance to toe off while in long leg it showed more increased flexion during stance phase. Faraj et al., [16] have studied LLD on plantar pressure contribution and compared the results between the normal individual and those of the individual with LLD shows that decrease in peak pressure.

During walking, there are many different of biomechanical changes on body postural and joint angle range of motion (ROM) occurs [9],[13]-[15], . Since ROM is a critical clinical parameter for diagnosing hip and knee diseases and for observing the procedure of treatment [19], [20]. This study was carried out to investigate the effect of different height of LLD on hip and knee joints range of motion.

\section{Methods}

\subsection{Participants}

Eighteen healthy males with no orthepadic disorders and normal BMI (age: $22.4 \pm 1.88$ years, height: $166.9 \pm 5.3 \mathrm{~cm}$ and weight: $62.86 \pm 7.84 \mathrm{~kg}$ ) among university populations participated in this experiment. All subjects have been given a consent form before starting the experiment.

\subsection{Experimental protocol}

Five set of cameras are used together with software Qualisys Track Manager (QTM) and two Bertec Corporation force plates 
on platform track with the default sampling frequency $(200 \mathrm{~Hz})$. A modified markers placement recommended from C-motion marker (plug-in-gait) set guidelines were applied to construct a biomedical model segment. 30 passive markers using double-sided adhesive tap were placed on the upper trunk (shoulder, lumbar spine), and on the lower limb (shank, tight, knee, ankle) and foot (heel, 1 st, 3rd and 5th metatarsals) for both legs. A pair of sandal that made of high-density ethylene vinyl acetate was attached to the feet bilaterally for both subjects to mimic LLD with Velcro TM straps. Before starting the experiment, the subject need to walk about three to five successful trial along the force platform to ensure the marker placement is strong enough, and also to help them familiar with the track. Then the subjects started to walk along 7 $\mathrm{m}$ distance on the track lab with $0.0 \mathrm{~cm}$ insole thickness on the long leg and increase it up to $4.0 \mathrm{~cm}$ with $0.5 \mathrm{~cm}$ increment each time along. The long limb needed to step fully on the first force plate and the short leg on the second force plate.

\subsection{Data analysis}

After the experiment done for all eighteen subjects, the data was collected and analyzed using QTM software to calculate the hip and knee ROM, Visual 3D software was used to identify the phases during walking. The joint angle calculated by QTM is follow the definition of international standard biomechanics (no reference line required to calculate the joint angle) [21]. The ROM of both legs for hip and knee joint was calculated as the maximum angle minus the minimum angle from initial contact until toe off for each side by considering sagittal and frontal plane [22]. The correlation coefficient test have been conducted to test the strength of the variables toward LLD level change [23].

\subsection{Statistical analysis}

The mean and standard deviations were calculated for each parameter to study subject characteristics. The Shapiro-Wilk test verified the normality assumption. One-way blocked analysis of variance (ANOVA) for repeated measurements were used as statistical method for normal distribution. The level of significance was set as $(\alpha=0.05)$, and correlation coefficient of 0.9 was interpreted as having a high correlation [11]. All statistical analyses were performed using IBM SPSS statistics 22 .

\section{Results}

\subsection{Hip joint ROM}

In Table 1, the mean of ROM for hip joint in frontal plane for short leg is slightly higher than mean of ROM for long leg. However, the mean of ROM in long leg became higher than short leg at LLD level of $2.0 \mathrm{~cm}$ and the long leg shows more higher at $3.5 \mathrm{~cm}$. This sudden change of mean values for ROM between short and long leg shows a significant difference for long leg. In addition, there was no significant difference effect observed for hip joint in frontal plane for short leg with LLD level $F(8$, 99) $=1.342, p=0.232$ and hence, the correlation coefficient between LLD level and hip frontal for short leg is shows a weak correlation $(\mathrm{r}=0.28)$ which indicate that hip joint ROM is not increasing so much once the LLD level change. A main effect found on hip joint for long leg in frontal plane $\mathrm{F}(8,106)=1.962, \mathrm{p}=0.050$ and it is clearly proved by the correlation coefficient value which shows moderately strong correlation $(r=0.4)$ for the hip joint ROM for long leg in frontal plane.

Table 1: Effect of LLD on hip joint ROM in frontal plane

\begin{tabular}{|c|c|c|c|}
\hline & \multicolumn{3}{|c|}{ ROM $_{\text {hip }}\left(^{\circ}\right)$} \\
\hline Level of LLD $(\mathrm{cm})$ & Short Leg & Long Leg & p-value \\
\hline 0.0 & $7.476 \pm 1.328$ & $6.181 \pm 1.800$ & 0.530 \\
\hline 0.5 & $7.574 \pm 1.940$ & $7.228 \pm 1.247$ & 0.620 \\
\hline
\end{tabular}

\begin{tabular}{|c|c|c|c|}
\hline 1.0 & $7.400 \pm 1.516$ & $6.418 \pm 1.373$ & 0.090 \\
\hline 1.5 & $7.548 \pm 1.696$ & $6.379 \pm 1.451$ & 0.098 \\
\hline 2.0 & $6.148 \pm 2.016$ & $6.810 \pm 1.998$ & 0.392 \\
\hline 2.5 & $7.447 \pm 1.362$ & $7.563 \pm 1.704^{*}$ & 0.854 \\
\hline 3.0 & $6.450 \pm 1.285$ & $8.140 \pm 1.466^{*}$ & 0.008 \\
\hline 3.5 & $7.715 \pm 1.173$ & $6.596 \pm 1.675^{*}$ & 0.080 \\
\hline 4.0 & $7.042 \pm 1.992$ & $7.025 \pm 1.534^{*}$ & 0.982 \\
\hline
\end{tabular}

*Significance difference at $\mathrm{p}<0.05$

The hip joint in sagittal plane demonstrates almost similar values of mean ROM for both legs. Somehow, the short leg seems to be slightly higher from $0.0 \mathrm{~cm}$ until $3.0 \mathrm{~cm}$ of LLD level and again the long leg has mean of ROM greater at $3.5 \mathrm{~cm}$ and $4.0 \mathrm{~cm}$. Table 2 shows that there was no main effect found on same joint for short leg with LLD level $F(8,106)=0.653, p=0.731$. No statistical significant effect found between hip joint for the long leg in sagittal plane with LLD height $F(8,98)=0.746, p=0.651$ and it has very strong correlation $(r=0.855)$ compared to hip joint in frontal plane but for short leg that has moderately strong correlation $(r=0.399)$.

Table 2: Effect of LLD on hip joint ROM in sagittal plane

\begin{tabular}{|c|c|c|c|}
\hline & \multicolumn{3}{|c|}{$\mathrm{ROM}_{\text {hip }}\left({ }^{\circ}\right)$} \\
\hline $\begin{array}{c}\text { Level of } \\
\text { LLD }(\mathrm{cm})\end{array}$ & Short Leg & Long Leg & p-value \\
\hline 0.0 & $23.068 \pm 2.998$ & $21.913 \pm 2.871$ & 0.357 \\
\hline 0.5 & $23.277 \pm 3.570$ & $22.556 \pm 3.813$ & 0.637 \\
\hline 1.0 & $22.008 \pm 3.984$ & $22.252 \pm 3.235$ & 0.867 \\
\hline 1.5 & $23.300 \pm 3.648$ & $22.296 \pm 4.441$ & 0.519 \\
\hline 2.0 & $23.057 \pm 2.783$ & $23.757 \pm 3.295$ & 0.587 \\
\hline 2.5 & $24.229 \pm 3.229$ & $23.705 \pm 4.024$ & 0.724 \\
\hline 3.0 & $22.651 \pm 3.165$ & $22.882 \pm 4.463$ & 0.891 \\
\hline 3.5 & $22.087 \pm 4.588$ & $24.451 \pm 2.494$ & 0.138 \\
\hline 4.0 & $21.661 \pm 3.534$ & $24.181 \pm 3.076$ & 0.074 \\
\hline
\end{tabular}

*Significance difference at $\mathrm{p}<0.05$

\subsection{Knee joint ROM}

The mean of ROM for knee joint in frontal plane shows higher values of short leg than long leg for all level of LLD. Clearly shown in Table 3 that there was no significant difference effect observed for knee joint in frontal plane for short leg with LLD level $F(8,109)=0.615, p=0.764$. Moreover, No statistical significant effect found between knee joint for the long leg in frontal plane with LLD height $\mathrm{F}(8,103)=0.934, \mathrm{p}=0.492$. Hence, the correlation was weak in knee joint ROM for long leg ( $\mathrm{r}$ $=0.36)$ and slightly strong at short leg $(\mathrm{r}=0.612)$.

Table 3: Effect of LLD on knee joint ROM in frontal plane

\begin{tabular}{|c|c|c|c|}
\hline & \multicolumn{3}{|c|}{ ROM $\left._{\text {knee }}{ }^{\circ}\right)$} \\
\hline Level of LLD $(\mathrm{cm})$ & Short Leg & Long Leg & p-value \\
\hline 0.0 & $11.122 \pm 2.643$ & $10.554 \pm 1.254$ & 0.557 \\
\hline 0.5 & $11.776 \pm 3.176$ & $9.700 \pm 1.876$ & 0.056 \\
\hline 1.0 & $12.084 \pm 2.739$ & $10.214 \pm 2.999$ & 0.098 \\
\hline 1.5 & $11.607 \pm 1.937$ & $9.625 \pm 3.064$ & 0.064 \\
\hline 2.0 & $11.107 \pm 2.399$ & $8.983 \pm 1.929$ & 0.028 \\
\hline 2.5 & $10.746 \pm 1.669$ & $9.308 \pm 1.991$ & 0.060 \\
\hline 3.0 & $11.084 \pm 2.210$ & $8.996 \pm 2.330$ & 0.025 \\
\hline 3.5 & $10.555 \pm 2.342$ & $10.595 \pm 2.199$ & 0.963 \\
\hline 4.0 & $10.949 \pm 1.687$ & $9.338 \pm 1.863$ & 0.038 \\
\hline
\end{tabular}

*Significance difference at $\mathrm{p}<0.05$

In contrast with sagittal plane for the same joint the mean of ROM is greater for long leg than short leg and it can be shown in Table 4 as there was a main effect on knee joint for long leg in sagittal plane $F(8,121)=3.578, p=0.001$. There was no main effect found on same joint for short leg using sagittal plane with LLD level $\mathrm{F}(8,109)=0.882, \mathrm{p}=0.534$. Therefore, the correlation coefficient was stronger in long leg that short leg $(r=0.67)$ and $(r$ $=0.523$ ) respectively. This demonstrates that the knee joint ROM is increasing in long leg than short leg. 
Table 4: Effect of LLD on knee joint ROM in sagittal plane

\begin{tabular}{|c|c|c|c|}
\hline & \multicolumn{3}{|c|}{$\operatorname{ROM}_{\text {knee }}\left({ }^{\circ}\right)$} \\
\hline $\begin{array}{c}\text { Level of } \\
\text { LLD }(\mathrm{cm})\end{array}$ & Short Leg & Long Leg & p-value \\
\hline 0.0 & $39.672 \pm 4.367$ & $40.400 \pm 2.841$ & 0.602 \\
\hline 0.5 & $40.199 \pm 3.396$ & $41.600 \pm 3.386$ & 0.296 \\
\hline 1.0 & $37.874 \pm 3.569$ & $44.415 \pm 4.055^{*}$ & 0.000 \\
\hline 1.5 & $40.099 \pm 3.447$ & $45.240 \pm 3.816^{*}$ & 0.001 \\
\hline 2.0 & $39.430 \pm 5.099$ & $42.447 \pm 3.799^{*}$ & 0.081 \\
\hline 2.5 & $39.854 \pm 3.796$ & $44.346 \pm 3.659^{*}$ & 0.003 \\
\hline 3.0 & $39.239 \pm 3.914$ & $43.764 \pm 2.226^{*}$ & 0.001 \\
\hline 3.5 & $37.375 \pm 4.266$ & $44.975 \pm 3.219^{*}$ & 0.000 \\
\hline 4.0 & $38.218 \pm 2.965$ & $44.611 \pm 2.525^{*}$ & 0.000 \\
\hline
\end{tabular}

$*$ Significance difference at $\mathrm{p}<0.05$

\section{Concluding remarks}

The study was conducted to observe the effect of different level of LLD on joint flexibility kinematics. From the results that gotten and observed, there was a statistically significance difference existed in hip and knee joint in early LLD and a statistically significant response between both sides. However, the results was somehow inconsistent and this difference of data might be because the participants employed opposite kinematic strategies to functionally lengthen their shorter limbs and shorten the longer limb mainly in the sagittal plane in accordance with previous studies [15]. Moreover, the gait is modifiable by changes in one's leg length, and the changes by the body to accommodate to this discrepancy are affected by intention, when the discrepancy is large.

\section{Acknowledgement}

The study was financially supported by the Ministry of Higher Education Malaysia Fundamental Research Grants Scheme (FRGS) (No: 9003-00579).

\section{References}

[1] KJ Murray \& Azari MF (2015), Leg length discrepancy and osteoarthritis in the knee, hip and lumbar spine. J. Can. Chiropr. Assoc., Vol. 59, No. 3, pp. 226-37.

[2] Azizan NA, Basaruddin KS, Salleh AF, Razak A, Juhairi M, Safar A, Mohd W \& Rusli R (2018), Leg Length Discrepancy: Dynamic balance response during gait. Journal of Healthcare Engineering.

[3] Azizan NA, Basaruddin KS \& Salleh AF (2018), Review Article The Effects of Leg Length Discrepancy on Stability and Kinematics-Kinetics Deviations : A Systematic Review. Applied Bionic and Biomechanics.

[4] Khalifa AA (2017), Leg Length Discrepancy: Assessment and Secondary Effects. Orthop. Surg. Dep., vol. 6, no. 1.

[5] Zabri SWKA, KS Basaruddin, Salleh AF, Rusli WMR \& Daud $\mathrm{R}(2017)$, Effect of leg length inequality on body weight distribution during walking with load: A pilot study. AIP Conference Proceedings, Vol. 1885.

[6] Zabri SWKA, Basaruddin KS, Salleh AF, Rusli WMR \& Basah SN (2018), Leg Length Inequality Effects on Ground and Lower Extremity Joint Reaction Forces during Walking. J. Telecommun. Electron. Comput. Eng., Vol. 10, No. 1, pp. 141-145.

[7] Saraph V, Zwick EB, Steinwender G, Auner C, Schneider F \& Linhart W (2006), Leg lengthening as part of gait improvement surgery in cerebral palsy: an evaluation using gait analysis. Vol. 23, pp. 8390.

[8] Othman NF, Basaruddin KS, Som MHM, Salleh AF, Sakeran H \& Daud R (2018), Effect of Leg Length Discrepancy on Joint Contact Force during Gait Using Motion Tracking System: A Pilot Test. J. Telecommun. Electron. Comput. Eng., Vol. 10, No. 1, pp. 125-129.

[9] De E (2007), Biomechanical Analysis of Hip and Knee Joints. J. Orthopaedlc Sport. Phys. Ther., vol. 15, pp. 267-271.

[10] Resende RA, Kirkwood RN, Deluzio KJ, Cabral S \& Fonseca ST (2016), Biomechanical strategies implemented to compensate for mild leg length discrepancy during gait. Gait Posture, Vol. 46, pp. 147-153.
[11] Resende RA, Kirkwood RN, Deluzio KJ, Morton AM \& Fonseca ST (2016), Mild leg length discrepancy affects lower limbs, pelvis and trunk biomechanics of individuals with knee osteoarthritis during gait. Clin. Biomech., Vol. 38, pp. 1-7.

[12] Yamin NAAA, Basaruddin KS, Rusli WMR, Salleh AF, Razak NA, \& Muhamad WZAW (2016), Effect of surface hardness on threesegment foot kinematics during barefoot running. Int. J. Mech. Mechatronics Eng., Vol. 16, No. 6, pp. 18-26.

[13] Azizan NA, Basaruddin KS, Salleh AF, Sakeran H, Sulaiman AR \& Cheng EM (2018), The Effect of Structural Leg Length Discrepancy on Vertical Ground Reaction Force and Spatial- Temporal Gait Parameter: Pilot Study," Vol. 10, pp. 1-5.

[14] Yamin NAAA, Amran MNA, Basaruddin KS, Salleh AF \& Rusli WMR (2017), Ground reaction force response during running on different surface hardness. ARPN J. Eng. Appl. Sci., vol. 12, no. 7.

[15] Khamis S \& Carmeli E (2018), The effect of simulated leg length discrepancy on lower limb biomechanics during gait. Gait Posture, Vol. 61, No. December 2017, pp. 73-80.

[16] Abu-faraj ZO, Ph D \& Member IS (2015), Leg Length Discrepancy: A Study on In-Shoe Plantar Pressure Distribution. 2015 8th Int. Conf. Biomed. Eng. Informatics (BMEI 2015), no. Bmei, pp. 381385.

[17] Venturni C, Andre A, Prates A \& Giacomelli B (2006), Reliability of two evaluation methods of active range of motion in teh ankle of healthy individuals. Rev. Acta Fisiátrica, vol. 13, no. 1, pp. 39-43.

[18] Hebenstreit F, Leibold A, Krinner S, Welsch G, Lochmann M \& Eskofier BM (2015), Effect of walking speed on gait sub phase durations. Hum. Mov. Sci., vol. 43, pp. 118-124.

[19] Yazdifar M, Yazdifar MR, Mahmud J, Esat I \& Chizari M (2013), Evaluating the hip range of motion using the goniometer and video tracking methods. Procedia Eng., Vol. 68, pp. 77-82.

[20] Kim SH, Kwon OY, Park KN, Jeon IC \& Weon JH (2015), Lower extremity strength and the range of motion in relation to squat depth. J. Hum. Kinet., vol. 45, no. 1, pp. 59-69.

[21] Fallis A (2013), Angular Kinematics. J. Chem. Inf. Model., vol. 53, no. 9, pp. 1689-1699.

[22] Mika A, Oleksy Ł, Mika P, Marchewka A \& Clark BC (2012), The influence of heel height on lower extremity kinematics and leg muscle activity during gait in young and middle-aged women. Gait Posture, vol. 35, no. 4, pp. 677-680.

[23] Mukaka MM (2013), Statistics corner: A guide to appropriate use of correlation coefficient in medical research. Malawi Med. J., vol. 24 , no. 3 , pp. $69-71$. 